\title{
Monitoring of Bone Metabolism after Bone Marrow Transplantation by Measuring Two Different Markers of Bone Turnover
}

\author{
Wolfgang Withold ${ }^{1}$, Hans-Heinrich Wolf ${ }^{2}$, Sabine Kollbach ${ }^{1,2}$, Axel Heyll $^{2}$, Wolfgang Schneider $^{2}$ and \\ Hans Reinauer ${ }^{1}$ \\ 1 Institut für Klinische Chemie und Laboratoriumsdiagnostik \\ 2 Klinik für Hämatologie, Onkologie und Klinische Immunologie \\ Heinrich-Heine-Universität Düsseldorf, Düsseldorf, Germany
}

\begin{abstract}
Summary: Bone marrow transplant recipients may be at increased risk of osteoporosis. In a cross-sectional study we therefore measured two biochemical markers of bone turnover, bone alkaline phosphatase and the C-terminal propeptide of type I procollagen, in 22 serum samples from 9 patients before allogeneic bone marrow transplantation and 85 serum samples from 14 patients after allogeneic bone marrow transplantation.
\end{abstract}

Following allogeneic bone marrow transplantation, female (but not male) patients showed elevated serum bone alkaline phosphatase values $(p<0.05)$. After bone marrow transplantation both female and male patients were characterized by elevated serum concentrations of the C-terminal propeptide $(p<0.01)$. Both the duration of cyclosporin A therapy $(p<0.05)$ and the time since transplantation $(p<0.01)$ were independent predictors of serum bone alkaline phosphatase values, whereas the duration of cyclosporin A therapy was the only independent predictor of C-terminal propeptide serum concentrations $(p<0.01)$. There was a correlation between bone alkaline phosphatase serum concentrations and C-terminal propeptide values in serum $(p<0.0001)$.

These findings indicate an accelerated bone turnover in patients following bone marrow transplantation due to the stimulation of osteoblasts by cyclosporin $\mathrm{A}$. In addition, oestrogen deficiency after total body irradiation may accelerate bone mass loss in female patients.

\section{Introduction}

Osteoporosis is a complication for which bone marrow transplant recipients may be at increased risk [for review see 1.c. (1)]:

(a) cyclosporin A therapy in immunosuppressive doses can induce osteopenia;

(b) glucocorticoids predispose to osteopenia by depressing bone formation and increasing bone resorption;

(c) sex hormone deficiency increases bone loss, especially in women following pretransplant conditioning with total body irradiation and chemotherapy.

Reduced bone mineral density in patients following bone marrow transplantation has already been shown (2). Bone alkaline phosphatase (EC 3.1.3.1) is an enzyme localized in the plasma membrane of osteoblastic cells (3). Type I collagen is the sole collagen type found in bones. The carboxy-terminal propeptide of procollagen type $\mathrm{I}$ is cleaved during extracellular processing of bone procollagen and appears in the blood (4). Both analytes may be considered as markers of bone turnover. In the present cross-sectional study we report on the diag- nostic validity of these biochemical markers in the follow-up of bone metabolism in patients receiving allogeneic bone marrow transplantation.

\section{Patients and Methods}

Patients

We examined

(a) 22 serum samples from 9 patients before allogeneic bone marrow transplantation (age: $35 \pm 2.2$ years) (mean $\pm S E M$ ) (5 males, 4 females) (4 chronic granulocyte leukaemia, 3 acute non-lymphoblastic leukaemia, 2 'high-grade' non-Hodgkin's lymphoma) and

(b) 85 serum samples from 14 patients after allogeneic bone marrow transplantation (age: $37 \pm 2.3$ years) (mean $\pm S E M)(10$ males, 4 females) ( 7 chronic granulocyte leukaemia, 4 acute nonlymphoblastic leukaemia, I acute lymphoblastic leukaemia, 2 'high-grade' non-Hodgkin's lymphoma).

The mean time since transplantation was $335 \pm 82$ (mean \pm SEM) days. The subjects received pretransplant conditioning with total body irradiation (10 Gy) and 'high-dose' cyclophosphamide (120 $\mathrm{mg} / \mathrm{kg}$ ). For prevention of graft-versus-host disease all patients received cyclosporin A ( $4 \mathrm{mg} / \mathrm{kg} \cdot \mathrm{d}$ i. v. then $12 \mathrm{mg} / \mathrm{kg} \cdot \mathrm{d}$ p. o.) for $216 \pm 45$ (mean \pm SEM) days and 'short-term' methotrexate (15 $\mathrm{mg} / \mathrm{m}^{2}$ body surface at day 1 and $10 \mathrm{mg} / \mathrm{m}^{2}$ body surface at days 3 and 6 after bone marrow transplantation). None of the patients received corticosteroids. Moreover, none of the female patients 
were receiving oestrogen therapy at the time of the study. All female patients following bone marrow transplantation had clinical and biochemical evidence of primary ovarian failure. The number of serum samples obtained from each patient ranged from 2 to 14 (mean: 5). None of the patients had any previous history of bone disease. Since this was a cross-sectional study, the patients examined before bone marrow transplantation were different from those examined after transplantation.

\section{Determination of serum analytes}

Bone alkaline phosphatase mass concentration in serum was determined by an immunoradiometric assay (Tandem ${ }^{\circledR}-\mathrm{R}$ Ostase ${ }^{\mathrm{TM}}$; Hybritech Inc., San Diego, CA [U.S. A.]; no. 3040 BE) employing two monoclonal antibodies against two different epitopes of the bone alkaline phosphatase molecule. A calibration curve was constructed by linear interpolation between the plotted analytical results. The following reference intervals $(2.5$ th -97.5 th percentile) for bone alkaline phosphatase concentration in serum were established in apparently healthy persons: (1) $3.8-21.3 \mu \mathrm{g} / 1$ (males, $\mathrm{n}=51)(2) 3.4-15.0 \mu \mathrm{g} / \mathrm{l}$ (females, $\mathrm{n}=51$ ); age range 20-55 years (males) and 18-56 years (females).

The concentration of the carboxy-terminal extension peptide of procollagen type $\mathrm{I}$ in serum was determined by an enzyme immunoassay (Prolagen-C $\mathrm{C}^{\mathrm{TM}}$; Metra Biosystems, Inc., Palo Alto, CA [U.S. A.]). A calibration curve was constructed by a 4-parameter curve fitting algorithm. The following reference intervals (2.5th-97.5th percentile) for the C-terminal propeptide in serum were established in apparently healthy persons: (1) $50-180 \mu \mathrm{g} / \mathrm{l}$ (males, $\mathrm{n}=51$ ) (2) $50-145 \mu \mathrm{g} / \mathrm{l}$ (females, $\mathrm{n}=51$ ); age range $23-$ 58 years (males) and $23-59$ years (females).

The urinary excretion of "pyridinium cross-links" of collagen was determined by a competitive enzyme immunoassay (Collagen Crosslinks $^{\mathrm{TM}}$ Kit; Metra Biosystems Inc.; Palo Alto, CA [U. S. A.]) employing a polyclonal antibody against pyridinoline which shows $100 \%$ cross-reactivity with deoxypyridinoline. A curve was constructed employing a 4-parameter curve fitting equation. The following reference interval (mean $\pm 2 \times \mathrm{SD}$ ) for the urinary excretion of pyridinium cross-links in 'second morning' urine samples was established in 40 apparently healthy female persons (agerange: $20-56$ years) (the samples were obtained between 8.00 and 10.00 a. m.): pyridinoline equivalents, $13-73 \mu \mathrm{mol} / \mathrm{mol}$ creatinine. The age distribution of these reference individuals did not significantly differ from that of the female patients examined (see above) $(\mathrm{p}>0.05)$.

Total alkaline phosphatase activity in serum was measured at $+25^{\circ} \mathrm{C}$ by the optimized standard method conforming to the Recommendations of the German Society for Clinical Chemistry (5) using the fully mechanized analyser Hitachi/BM 737 (Boehringer Mannheim $\mathrm{GmbH}$, Mannheim, Germany) (reference range: 78$178 \mathrm{U} / \mathrm{l}$ [males] and 59-160 U/I [females]).

Serum $\gamma$-glutamyl transferase activity was measured at $+25^{\circ} \mathrm{C}$ according to Szász (6) using the fully mechanized analyser Hitachi/ BM 737 (Boehringer Mannheim GmbH, Mannheim, Germany) (reference range: 6-28 U/l [males] and 4-18 U/l [females]).

\section{Statistical analysis}

As statistical methods we used the U-test according to Wilcoxon, Mann \& Whitney (two-tailed) for unpaired samples, linear regression equations, and linear correlation coefficients (7).

Multiple regression analysis was performed with the help of SPSS/ $\mathrm{PC}+{ }^{\mathrm{TM}}$ V2.0 employing the procedure REGRESSION with a 'stepwise' selection of the independent variables. An association between the values of the bone metabolism markers and liver dysfunction (as assessed by $\gamma$-glutamyl transferase activities) was examined by analysis of variance employing the procedure 'ANOVA' (SPSS/PC $+{ }^{\mathrm{TM}}$ V2.0).

All values are given as mean \pm SEM.

\section{Results}

Values of bone turnover markers before and after allogeneic bone marrow transplantation

Comparison of the mean values from each patient showed that the serum bone alkaline phosphatase values of female patients were higher after than before allogeneic bone marrow transplantation: $14.4 \pm 2.0 \mu \mathrm{g} / 1$ (after) vs $7.3 \pm 1.0 \mu \mathrm{g} / \mathrm{l}$ (before) $(\mathrm{p}<0.05)$. This did not apply to male patients: $13.1 \pm 1.9 \mu \mathrm{g} / \mathrm{l}$ (after) vs $13.1 \pm 1.8$ $\mu \mathrm{g} / \mathrm{l}$ (before) $(\mathrm{p}<0.5)$.

To assess whether the increased values of serum bone alkaline phosphatase actually reflect increased bone turnover, we determined the "pyridinium cross-links" of collagen in 'second morning' urine samples (collected between 8.00 and $10.00 \mathrm{a}$. m.) corresponding to those sera obtained from female patients following bone marrow transplantation. There was a significant increase in the urinary excretion of this bone resorption marker (56 $\pm 9 \mu \mathrm{mol} / \mathrm{mol}$ creatinine) as compared to an ageand sex-adjusted control collective (see Materials and Methods) $(\mathrm{p}<0.05)$.

The values of serum total alkaline phosphatase activity showed the same behaviour except that the increase in total alkaline phosphatase activity (as found in female patients) did not attain the significance level: $143 \pm 34$ $\mathrm{U} / 1$ (after) vs $85 \pm 5 \mathrm{U} / \mathrm{l}$ (before) $(\mathrm{p}=0.083)$ [females] and $143 \pm 18 \mathrm{U} / 1$ (after) vs $124 \pm 17 \mathrm{U} / 1$ (before) (p > 0.5) [males].

After bone marrow transplantation both female and male patients had higher concentrations of the C-terminal propeptide in their serum: $118 \pm 9 \mu \mathrm{g} / \mathrm{l}$ (after) vs $65 \pm 5$ $\mu \mathrm{g} / \mathrm{l}$ (before) $(\mathrm{p}<0.01)$. There was a concomitant increase of serum $\gamma$-glutamyl transferase activity following bone marrow transplantation $(33 \pm 7 \mathrm{U} / 1$ [after] vs $14 \pm 3 \mathrm{U} / 1$ [before] $)(\mathrm{p}<0.01)$.

\section{Relationship between total alkaline} phosphatase activities, bone alkaline phosphatase concentrations and C-terminal propeptide levels

There was a relationship between bone alkaline phosphatase serum concentrations and total alkaline phosphatase activities/C-terminal propeptide' serum values ( $<<0.0001$ ) (fig. 1). Increased bone alkaline phosphatase concentrations $(>21.3 \mu \mathrm{g} / 1$ [males] and $>15.0 \mu \mathrm{g} / 1$ [females]) were found in $14(20 \%)$ of 70 serum samples which were characterized by a total alkaline phosphatase activity below the upper reference limit (178 U/1 [males] and $160 \mathrm{U} / 1$ [females]) and in $13(18 \%)$ of 74 serum samples which showed C-terminal propeptide values below the upper reference limit (180.jp/1 [males] and 145 $\mu \mathrm{g} / \mathrm{l}$ [females]). 
a)

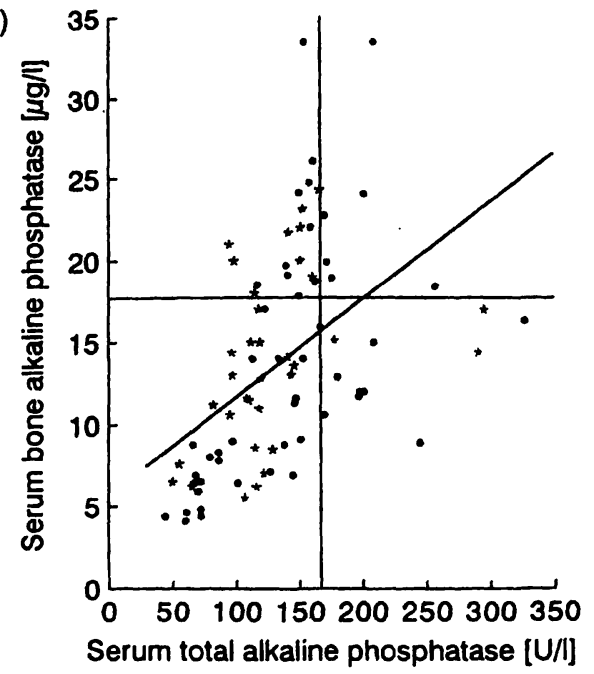

Fig. 1 Relationship between total alkaline phosphatase activities, bone alkaline phosphatase values and C-terminal propeptide serum concentrations in patients after bone marrow transplantation.

Values are given for all 85 serum samples examined following bone marrow transplantation. The horizontal and vertical lines (fig. $1 \mathrm{a}$ and $1 \mathrm{~b}$ ) denote the upper reference limits (97.5th percentile) established in 102 reference individuals without taking into consideration the dependence of reference values upon sex (167 U/1 for total alkaline phosphatase activity, $17.7 \mu \mathrm{g} / \mathrm{l}$ for bone alkaline

\section{Relative effects of various influences on the values of bone turnover markers}

Both before and after bone marrow transplantation there was no significant association between total alkaline phosphatase activities, bone alkaline phosphatase concentrations and $\mathrm{C}$-terminal propeptide values on the one hand, and $\gamma$-glutamyl transferase activities (increased or not increased above the upper reference limit) on the other $(p>0.5)$.

The values of both bone formation markers were increased within the first year after bone marrow transplantation $(p<0.0001)$ in all the 85 sera examined following allogeneic bone marrow transplantation. Subsequently the serum concentrations of bone alkaline phosphatase significantly decreased $(p<0.01)$, whereas the decrease of the C-terminal propeptide values in serum did not attain significance level $(p=0.307)$ (fig. 2).

The relative effects of various influences on the values of the bone formation markers within the first year after allogeneic bone marrow transplantation were analysed individually and by multiple regression analysis. The independent variables included were creatinine concentration in serum, serum $\gamma$-glutamyl transferase activity, duration of cyclosporin A therapy, time since transplantation, age of patients and whether the subjects suffered from chronic graft-versus-host disease or not. Both duration of cyclosporin A therapy $(p<0.05)$ and time since transplantation $(p<0.01)$ were independent predictors of serum bone alkaline phosphatase values, whereas the duration of cyclosporin A therapy was the only indepen-

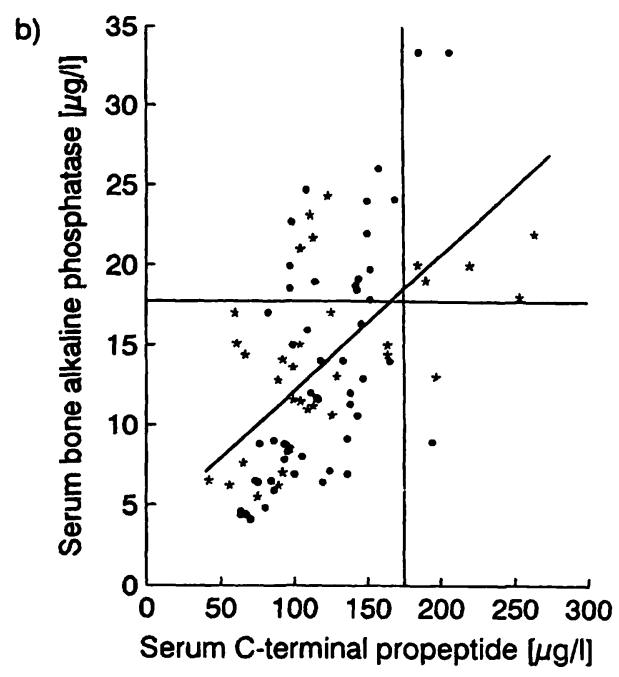

phosphatase concentration and $175 \mu \mathrm{g} / \mathrm{l}$ for the C-terminal propeptide). Sera obtained from females are designated by stars, those collected from males by dots.

The relationships between the quantities are given by the following regression equations: Serum bone alkaline phosphatase $[\mu \mathrm{g} / 1]$ $=0.060 \times$ serum total alkaline phosphatase $[\mathrm{U} / 1]+5.70$ $(r=+0.499 ; p<0.0001)$ (fig. 1a).

Serum bone alkaline phosphatase $[\mu \mathrm{g} / 1]=0.085 \times$ serum $\mathrm{C}$-terminal propeptide $[\mu \mathrm{g} / \mathrm{l}]+3.68(\mathrm{r}=+0.560 ; \mathrm{p}<0.0001)$ (fig. $\mathrm{lb})$.

dent predictor of C-terminal propeptide serum concentrations $(p<0.01)$.

\section{Discussion}

In females but not in males there was a significant difference between serum bone alkaline phosphatase values before and after allogeneic bone marrow transplantation. This may be explained by the influence of primary ovarian failure following total body irradiation, whereas in men only a moderate elevation of gonadotropins as well as testosterone levels within the reference interval were observed $(2,8)$. Cyclosporin A may enhance the deleterious effect of oestrogen deficiency, since in oophorectomized rats bone mass loss is accelerated by the application of cyclosporin A (9).

Cyclosporin A is known to produce high bone remodelling with bone resorption exceeding bone formation after daily oral cyclosporin doses between 7.5 and 15 $\mathrm{mg} / \mathrm{kg}$ body weight in rats $(10,11)$; this essentially corresponds to the oral dose given to our patients. In patients under immunosuppressive therapy with cyclosporin A a comparable increase of serum (bone) alkaline phosphatase activities was observed after renal transplantation (12-14).

Carlson et al. (15) found a depression of bone formation within the first three months following bone marrow transplantation which is probably due to

(a) an inhibitory effect of glucocorticoids upon bone formation, 


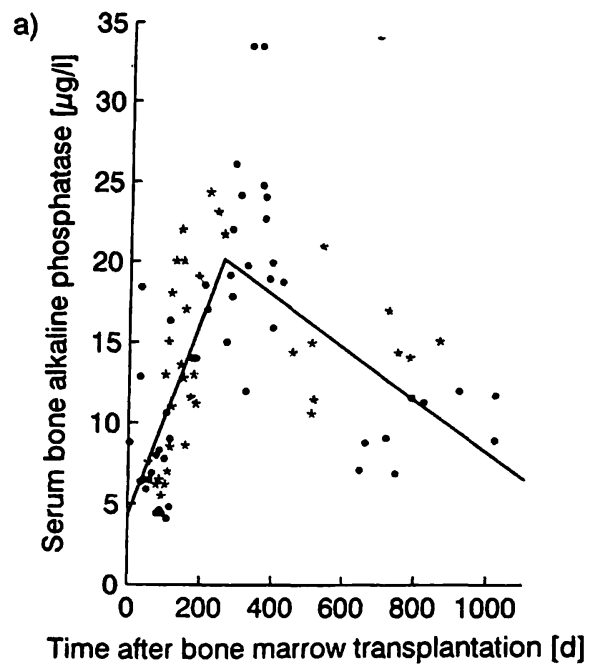

Fig. 2 Relationship between bone alkaline phosphatase serum levels/C-terminal propeptide serum values and time since transplantation.

The relationship between serum bone alkaline phosphatase values and time since transplantation is given by the following regression equations (fig. 2a):

Serum bone alkaline phosphatase $[\mu \mathrm{g} / \mathrm{l}]=0.061 \times$ time since transplantation [d] $+4.26(\mathrm{r}=+0.782 ; \mathrm{p}<0.0001)$ (time since transplantation $\leq 365$ days).

Serum bone alkaline phosphatase $[\mu \mathrm{g} / 1]=-0.016 \times$ time since transplantation [d] $+24.30(\mathrm{r}=-0.599 ; \mathrm{p}<0.01)$ (time since transplantation $>365$ days).

(b) damage to osteoprogenitor cells by the myeloablative therapy and

(c) an inhibition of osteoblast function by locally secreted cytokines.

However, there are some differences between the present study and that reported by Carlson et al. (15):

(a) The follow-up period of Carlson's study was only 3 months following bone marrow transplantation whereas in the present communication the mean time since transplantation was 335 days. The suppressive effect on osteoblast function reported (15) was only transient, and normal values of bone alkaline phosphatase were regained after 3 months; alterations of cytokine secretion are most strongly pronounced immediately after bone marrow transplantation. In contrast, in patients receiving renal transplants, an activating effect of cyclosporin A upon osteoblast activity (detected by determination of bone turnover markers) can be found 3 months at the earliest after transplantation (12). Due to the cross-sectional character of our study and the much longer follow-up period we were therefore not able to detect the slight suppressive effects on bone formation shown by Carlson et al. (15).

(b) No glucocorticoids were given to our patients.

Reduced bone mineral density is a common finding in patients following liver, cardiac and bone marrow transplantation $(2,16-18)$. Kelly et al. (2) showed that in patients following bone marrow transplantation there is no relationship between bone mineral density and dura-

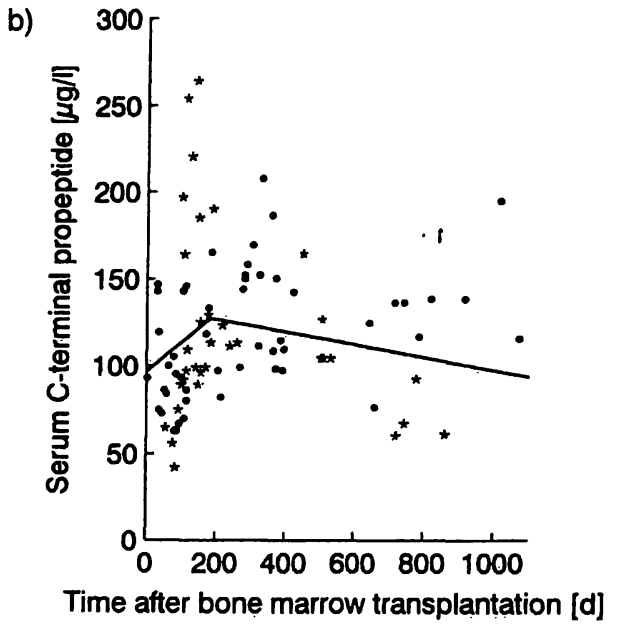

The relationship between serum C-terminal propeptide values and time since transplantation is given by the following regression equations (fig. 2b):

Serum C-terminal propeptide $[\mu \mathrm{g} / \mathrm{l}]=0.168 \times$ time since transplantation [d] $+96.41(\mathrm{r}=+0.320 ; \mathrm{p}<0.05)$ (time since transplantation $\leq 365$ days).

Serum C-terminal propeptide $[\mu \mathrm{g} / 1]=-0.037 \times$ time since transplantation [d] $+133.70(r=-0.228 ; p=0.307)$ (time since transplantation $>365$ days).

Sera obtained from females are designated by stars, those collected from males by dots.

tion of cyclosporin A therapy. This may be due to the fact that some of their patients additionally received glucocorticosteroids.

It has previously been shown in patients with various types of metabolic bone diseases that the serum concentrations of the C-terminal propeptide correlate with histomorphometric variables of bone formation (19). Corresponding to our findings, a correlation between C-terminal propeptide serum values and serum alkaline phosphatase activities has been observed in cancer patients (20) and in patients with metabolic bone diseases (19).

In the interpretation of C-terminal propeptide serum concentrations, account must be taken of the fact that a disturbed liver function may result in high serum values, probably due to the involvement of liver endothelial cells in the metabolic clearance of this molecule (19, 21). Despite the significant increase of serum $\gamma$-glutamyl transferase activities following bone marrow transplantation, a major influence of liver function on C-terminal propeptide serum values seems improbable in the present study, because

(a) serum $\gamma$-glutamyl transferase activity was not an independent predictor of C-terminal propeptide serum values as shown by multiple regression analysis, and

(b) 'analysis of variance' revealed no statistically significant association between $\gamma$-glutamyl transferase activities and the values of this bone metabolism marker.

It is worth mentioning that bone allkaline phosphatase serum concentrations were increased in $20 \%$ of samples 
with total alkaline phosphatase activities within the reference range, as well as in $18 \%$ of samples with Cterminal propeptide serum values within the reference range. This indicates that bone alkaline phosphatase concentrations are more sensitive than the other two measurable quantities in the detection of disturbances of bone metabolism (12). Therefore in patients following

\section{References}

1. Katz IA, Epstein S. Posttransplantation bone disease. J Bone Miner Res 1992; 7:123-6.

2. Kelly PJ, Atkinson K, Ward RL, Sambrock PN, Biggs JC, Eisman JA. Reduced bone mineral density in men and women with allogeneic bone marrow transplantation. Transplantation 1990; 50:881-3.

3. Van Straalen JP, Sanders E, Pummel MF, Sanders GTB. Bonealkaline phosphatase as indicator of bone formation. Clin Chim Acta 1991; 201:27-34.

4. Melkko J, Niemi S, Risteli L, Risteli J. Radioimmunoassay of the carboxyterminal propeptide of human type I procollagen. Clin Chem 1990; 36:1328-32.

5. Bergmeyer HU, Büttner $\mathrm{H}$, Hillmann $\mathrm{G}$, Kreutz FH, Lang $\mathrm{H}$, Laue D, et al. Empfehlungen der Deutschen Gesellschaft für Klinische Chemie. Standardisierung von Methoden zur Bestimmung von Enzymaktivitäten in biologischen Flüssigkeiten. Experimentelle Begründung der optimierten Standard-Bedingungen. Z Klin Chem Klin Biochem 1972; 10:182-92.

6. Szász G. $\gamma$-Glutamyl-Transpeptidase. In: Bergmeyer HU, editor. Methoden der enzymatischen Analyse. Weinheim: Verlag Chemie, 1974:757-62.

7. Sachs L. Statistische Methoden. Planung und Auswertung. 6th ed. Berlin, Heidelberg, New York, London, Paris, Tokyo: Springer, 1988.

8. Benker G, Schäfer U, Hermanns U, Mahmoud MK, Olbricht $\mathrm{T}$, Schulte HM, et al. Allogeneic bone marrow transplantation in adults: endocrine sequelae after $1-6$ years. Acta Endocrinol (Copenh) 1989; 120:37-42.

9. Joffe I, Katz I, Jacobs T, Stein B, Takizawa M, Liu C, Berlin $\mathrm{J}$, Epstein S. $17 \beta$-estradiol prevents osteopenia in the oophorectomized rat treated with cyclosporin A. Endocrinology 1992; 130:1578-86.

10. Movsowitz C, Epstein S, Fallon M, Ismail F, Thomas S. Cyclosporin-A in vivo produces severe osteopenia in the rat: effect of dose and duration of administration. Endocrinology 1988; 123:2571-7.

11. Stein B, Takizawa M, Schlosberg M, Movsowitz C, Fallon M, Berlin JA, Epstein S. Evidence that cyclosporine G is less deleterious to rat bone in vivo than cyclosporin A. Transplantation 1992; 53:628-32.

12. Withold W, Degenhardt S, Castelli D, Heins M, Grabensee B. Monitoring of osteoblast activity with an immunoradiometric bone marrow transplantation, bone alkaline phosphatase in particular may be a useful marker substance for detection of increased bone turnover.

\section{Acknowledgements}

The technical help of Miss $J$. Kennel is gratefully acknowledged. assay for determination of bone alkaline phosphatase mass concentration in patients receiving renal transplants. Clin Chim Acta $1994 ; 225: 137-46$

13. Loertscher R, Thiel G, Harder F, Brunner FP. Persistent elevation of alkaline phosphatase in cyclosporine-treated renal transplant recipients. Transplantation 1983; 35:115-6.

14. Schmidt H, Stracke H, Schatz H, Scheuermann EH, Fassbinder W, Schoeppe W. Osteocalcin serum levels in patients following renal transplantation. Klin Wochenschr 1989; 67:297-303.

15. Carlson K, Simonsson B, Ljunghall S. Acute effects of highdose chemotherapy followed by bone marrow transplantation on serum markers of bone metabolism. Calcif Tissue Int 1994; $55: 408-11$

16. Arnold JC, Hauser D, Ziegler R, Kommerell B, Otto G, Theilmann $\mathrm{L}$, Wüster $\mathrm{C}$. Bone disease after liver transplantation. Transplant Proc 1992; 24:2709-10.

17. Eastell R, Dickson ER, Hodgson SF, Wiesner RH, Porayko MK, Wahner HW. Rates of vertebral bone loss before and after liver transplantation in women with primary biliary cirrhosis. Hepatology 1991; 14:296-300.

18. Shane E, Rivas MC, Silverberg SJ, Kim TS, Staron RB, Bilezikian JP. Osteoporosis after cardiac transplantation. Amer J Med 1993; 94:257-64.

19. Eriksen EF, Charles P, Melson F, Mosekilde L, Risteli L, Risteli J. Serum markers of type I collagen formation and degradation in metabolic bone disease: correlation with bone morphometry. J Bone Min Res 1993; 8:127-32.

20. Francini G, Gonnelli S, Petrioli R, Bruni S, Marsili S, Aquino A, Camporeale A. Procollagen type I carboxy-terminal propeptide as a marker of osteoblastic activity. Cancer Epidemiol Biomarkers Prev 1993; 2:125-9.

21. Smedsrod B, Melkko J, Risteli L, Risteli J. Circulating C-terminal propeptide of type I procollagen is cleared mainly via the mannose receptor in liver endothelial cells. Biochem $J$ $1990 ; 271: 345-50$.

\section{Received September 4/November 24, 1995}

Corresponding author: Dr. med. Wolfgang Withold, Institute for Clinical Chemistry and Laboratory Diagnostics, Heinrich-HeineUniversity of Düsseldorf, Moorenstraße 5, D-40225 Düsseldorf, Germany 


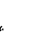

